\title{
"An investigation into the career path of Non-Commissioned Officers (NCOs) in the Defence Forces of Ireland (Army only) on retirement"
}

Ray Whelan and Dr. Sharon Feeney 


\section{General MacArthur}

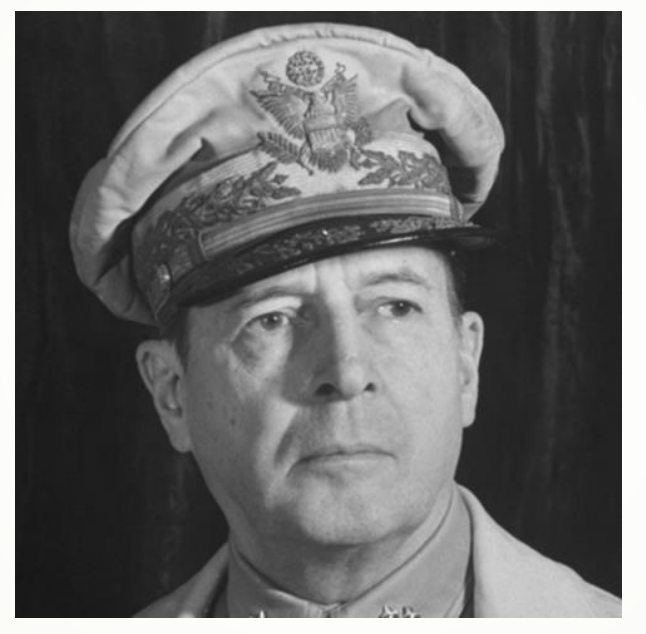

"Old Soldiers never die, they just fade away" 


\section{A little bit about the speaker}

- Served 22 years in the Defence Forces, retiring in 2002 as a Company Sergeant

- Served 3 six month tours of South Lebanon with UNIFIL in an Infantry Company

- A large majority of that time was spend in a training Unit that specialised in conducting courses transiting civilians into professional soldiers and conducting promotion and general training with a Brigade formation

- Holds an MS.c in HRM and is currently conducting corporate training and Lecturing

- The research was conducted as part of my MS.c in 2015 


\section{Abstract}

- The Irish Defence (DF) has three branches:

- The Army

- The Navy

- The Air Corp

- It has an established strength of 9,500, the current strength is just over 9,000

- There are approx 3,139 Non-Commissioned Officers in the Defence Forces

- The DF underwent a major restructure in 2012

- It has an excellent international reputation in peace keeping and peace enforcement across the globe

- There are approx 1,692 DF personnel deployed across 14 Countries on UN mandated peace support and security missions 


\section{Why do research into this topic?}

- Military careers are unique in respect to the following points:

- There is a transition period from civilian into military life, and then at the end they have to transit back to civilian life

- Everybody gets the same basic training this normally lasts up 4 months, however training and education is ongoing throughout their careers

- They learn a numerous skills that can be transferrable into civilian organisations

- The cost to train military personnel up to retirement age can vary depending how much specialist train int they receive

- This is tax payers money

- The upper age limit is 60 , in todays terms 60 is no longer seen as old, depending on your physical condition 


\section{Why so much talk about the concept of transiting}

- The transformation from civilian to professional could take up two years to be fully complete, however it could take longer depending on the length of service

- It can be very physical and emotionally draining, and anybody who has every done recruit training only ever wants to do it once

- Your life becomes consumed and even basic decisions like eating and sleeping are controlled by the military staff

- It can be difficult for some people to let go of their civilian thoughts and habits and learn new ones

- Once the initial induction is over it becomes easier, however the most difficult transition is that back to civilian life 


\section{Why so much talk about the concept of transiting}

- Research has shown particular from Mc Dermot (2007) that the longer the individual serves the harder it will be to make the transition back to civilian life

- The concept of culture dependence or what we commonly called in the military "Institution" can be very difficult for some individuals

- The main reason for this difficult is the lack of preparation, if you look how long it takes to become a professional solider and all the pain that goes with it, at the other end there is very little time to prepare and very little if any guidance

- The whole concept of return on investment is the next point, should the tax payer not seek a return on the investment and should the military not help those leaving get position to under pin that investment 


\section{The research}

- Qualitative research was conducted by me on this topic

- I carried out five interviews with retired NCO's, for the main reasons as follows:

- I wanted to see what skills had each individual brought with them to civilian life? and did they have any common skills?

- Did they think the skills they acquired in the DF helped them in civilian life?

- Lastly did the DF do enough to help the transition period? 


\section{Profile of the people}

- The five people interviewed are currently employed as follows:

- A Barrister

- An IT Lecturer

- A stunt man in the film business

- Head of security in Dublin Port

- One starting their own business

- The various roles were a good indication of the variety of positions former NCO's transit to. It's a testimony to their individual determination and their ability to utilises their skill set

- They also cited the fact that learning in the DF is both formal and informal 


\section{What skills had they brought into civilian life}

- Teamwork

- Planning and organising

- Leadership

- Motivation

- These were the main competencies centred around their individual skill set and they were learned both formally and informally, what do these two terms actual mean in military context?

- Formal: The new recruit or the trained soldier in training will pend many hours practicing their craft with formal instruction from their instructors

- Informal: many hours are spend outside normal training hours with the soldiers reinforcing Unit and DF ethos and building self confidence 


\section{Did they think these skills helped in their civilian positions}

- The answer here was a big "Yes" having experienced civilian organisations for the last ten years, the competencies they learnt previously are the very ones civilian recruiter seek

- The advantage the military people have is they have practised their skills where the environment was extreme and often dangerous example Leadership and Teamwork.

- Lastly did the DF do enough to help the transition period?

- There was some token effort made to help with the transition back to civilian life, but nothing like the time, money and effort that was spend on the way in to the military. 


\section{Summary}

- Former members of the DF can add great value to any civilian organisation

- The training and service overseas allows them this unique opportunity to practise their skills in extreme environments the very skills every organisation needs

- The DF need to think about how the tax payer can get a better return on its investment

- The power of the formal and informal training is vital to the development of the four competencies

- Its equally important that the individual making the transition understands their skill set and transfers them into a language that civilians can understand 